\title{
BIOCOMPÓSITOS DE POLÍMERO NATURAL REFORÇADO COM FIBROÍNA: AVALIAÇÃO DO CONTEÚDO DE FIBRAS NO EFEITO DO REFORÇO
}

\author{
C. G. $\operatorname{COSTA}^{1}$, L. F. R. P. BOM${ }^{1}$, C. R. MARTINS ${ }^{1}$, M. A. MORAES ${ }^{1}$ \\ ${ }^{1}$ Universidade Federal de São Paulo, Departamento de Engenharia Química \\ E-mail para contato: carolgrecosta@gmail.com
}

\begin{abstract}
RESUMO - A utilização da fibroína como fibra de reforço em biocompósitos torna-se atrativa, especialmente para aplicação em biomateriais, visto que possui entre suas características biocompatibilidade, mínima reação inflamatória e boas propriedades mecânicas. Além da escolha das fibras, a quitosana torna-se interessante para ser utilizada como matriz visto que exibe características como propriedade hemostática, boa permeabilidade ao oxigênio e boa absorção de água. Sendo assim, tendo como foco a utilização de biocompósitos de quitosana reforçados com fibroína para aplicações em curativos de alto desempenho, foi realizado o estudo do conteúdo (fração mássica) de fibras nos biocompósitos de quitosana. No caso do preparo das fibras, foi realizada a remoção da sericina dos casulos utilizando-se $\mathrm{Na}_{2} \mathrm{CO}_{3} 1 \mathrm{~g} / \mathrm{L}$ e banho termostatizado à $85^{\circ} \mathrm{C}$. Após secas, as fibras foram picadas. Para o preparo da matriz, foi utilizada solução de quitosana $1 \%(\mathrm{~m} / \mathrm{v})$ em ácido acético $2 \%(\mathrm{v} / \mathrm{v})$. Foram inseridos $20 \%$ ou $60 \%$ em fração mássica das fibras na matriz e empregou-se o método de casting e evaporação do solvente e reticulação em NaOH 1 mol/L. A membrana com $60 \%$ em fração mássica de fibras apresentou um melhor resultado $(1,8071 \pm 0,4049)$ quando analisado com o grau de intumescimento da membrana com $20 \%(1,4211$ $\pm 0,1312$ ). Já no caso do teste mecânico, a membrana com $20 \%$ em fração mássica de fibras mostrou-se mais resistente apresentando tensão de ruptura de 18,743 \pm $5,860 \mathrm{MPa}$, enquanto que a membrana com $60 \%$ apresentou tensão de ruptura de $6,820 \pm 3,591 \mathrm{MPa}$. Além disso, ambas as membranas não apresentaram perda de massa em PBS, evidenciando eficácia no processo de reticulação. Com isso, como o objetivo é a obtenção de membranas resistentes, maleáveis e com boa absorção, a membrana com $20 \%$ em fração mássica de fibras mostrou resultados mais satisfatórios do que a membrana com $60 \%$.
\end{abstract}

\section{INTRODUÇÃO}

A fibroína de seda é uma proteína fibrosa produzida pelo bicho-da-seda. É possível a obtenção de até $1000 \mathrm{~m}$ de fibras de fibroína de um único casulo pela remoção da sericina por imersão em água fervente ou solução alcalina (Vepari, 2007; Plaza et al., 2008). Sua 
utilização como fibra de reforço em biocompósitos poliméricos para aplicações biomédicas torna-se interessante devido a sua boa biocompatibilidade, biodegradabilidade, mínima reação inflamatória, possibilidade de esterilização e preparo em diversos formatos, boas propriedades mecânicas, permeabilidade ao oxigênio e vapor d'água, alta estabilidade térmica e resistência a microorganismos (Li et al., 2002; Altman et al., 2003).

Além da preocupação com a escolha das fibras, as propriedades da matriz também são essenciais no preparo de biocompósitos. Sendo assim, a utilização da quitosana torna-se interessante, resultando em um biocompósito biocompatível, com potencial para aplicação como biomaterial. A quitosana é um produto da desacetilação da quitina, extraída da carapaça de crustáceos, como o camarão, o caranguejo e o siri, e também de insetos e parede celular de alguns fungos. Ela vem sendo estudada extensivamente como curativo na cicatrização de ferimentos e queimaduras por exibir propriedade hemostática, boa permeabilidade ao oxigênio, boa absorção de água e atuar na migração de fibroblastos e células endoteliais.

Nesse contexto, o estudo de biocompósitos de quitosana reforçado com fibroína para aplicação como curativos torna-se interessante devido à busca de materiais com resistência mecânica, maleabilidade e boa absorção de água.

\section{OBJETIVOS}

O objetivo desse projeto é o estudo do conteúdo (fração mássica) de fibras de fibroína no reforço de biocompósitos de quitosana para aplicações em curativos de alto desempenho.

\section{METODOLOGIA}

\subsection{Preparação dos biocompósitos}

Os biocompósitos foram preparados utilizando casulos do bicho-de-seda. Inicialmente foi feita a remoção da sericina dos casulos, a fim de evitar problemas de hipersensibilidade à seda (Altman et al., 2003). Para isso, cada 50,0 g de matéria-prima foram lavados em 600,0 $\mathrm{mL}$ de solução aquosa de $\mathrm{Na}_{2} \mathrm{CO}_{3} 1,0 \mathrm{~g} / \mathrm{L}$, durante $30 \mathrm{~min}$, em banho termostatizado, à temperatura de $85{ }^{\circ} \mathrm{C}$. Este procedimento foi repetido três vezes e, ao final, as fibras de fibroína obtidas foram lavadas com água destilada em abundância. As fibras foram secas por 24 a 48 h (Li et al., 2002). Em seguida, as fibras foram picadas com tesoura em pedaços de, aproximadamente, 2,0 a 3,0 $\mathrm{mm}$.

Foi utilizada solução de quitosana $1 \%(\mathrm{~m} / \mathrm{v})$ em ácido acético $2 \%(\mathrm{v} / \mathrm{v})$ para o preparo da matriz. Foram inseridos $20 \%$ ou $60 \%$ em massa das fibras na matriz. O método de casting e evaporação do solvente foi empregado para o preparo dos biocompósitos. Em seguida, para a estabilização da quitosana foi necessário realizar a imersão das matrizes em solução de $\mathrm{NaOH} 1,0 \mathrm{~mol} / \mathrm{L}$ por $24 \mathrm{~h}$. 


\subsection{Caracterização das matrizes poliméricas e dos biocompósitos}

Antes da realização dos testes, todas as amostras foram equilibradas em umidade relativa de $52 \%$ por $48 \mathrm{~h}$.

Foram realizados testes mecânicos de resistência à tração, a fim de se verificar o efeito de reforço associado à inclusão de diferentes porcentagens das fibras de fibroína nos biocompósitos. Foram obtidas 7 medidas de espessura de uma amostra de 10,0 x 2,5 cm. Em seguida, foi utilizado o "Brookfield Engineering Texture Pro CT v1.2 build 9" sendo as garras distanciadas $5,0 \mathrm{~cm}$ e a taxa de deformação ajustada para $0,1 \mathrm{~cm} / \mathrm{s}$. Para a realização desse procedimento, a norma ASTM D882 (ASTM, 1995) foi seguida. A partir dos dados obtidos, foi possível determinar a tensão de ruptura da membrana pela Equação 1 e o alongamento na ruptura pela Equação 2. Para o cálculo do Módulo de Young, foram utilizados os valores do módulo tangente da inclinação da curva tensão-deformação durante a fase de elongação elástica.

$$
\begin{aligned}
& T R=\frac{F m}{A s} \\
& A=\left(\frac{d r-d i}{d i}\right) 100
\end{aligned}
$$

Também foi feito o estudo do grau de intumescimento das membranas em PBS. Para isso, a massa de uma amostra de 2,0 x 1,0 cm foi quantificada. Em seguida, a amostra foi colocada em 5,0 mL de PBS e pesada a cada intervalo de 30 segundos até que fossem completados 3 minutos. Antes de completar os 3 minutos já havia se observado massa constante. Entretanto, para se obter mais dados, após esse tempo, ela foi pesada a cada 1 minuto até que fossem completados mais 3 minutos. O procedimento foi realizado em triplicata para cada membrana e o grau de intumescimento foi calculado pela Equação 3.

$$
G I=\frac{m f-m i}{m i}
$$

Além desses dois testes, também foi realizado o teste de perda de massa durante exposição em PBS. Uma amostra retangular de $6,0 \times 1,0 \mathrm{~cm}$ foi quantificada. Em seguida, foi imersa em $10,0 \mathrm{~mL}$ de PBS por 7 dias a $37^{\circ} \mathrm{C}$. O corpo de prova foi seco por $24 \mathrm{~h}$, a $37^{\circ} \mathrm{C}$, mantido em dessecador com umidade relativa $52 \%$ por 48 h e novamente quantificado. $\mathrm{O}$ procedimento foi realizado em triplicata para cada membrana e a perda de massa em PBS foi calculada pela Equação 4.

$$
M p=\left(\frac{m i-m f}{m i}\right) 100
$$

\section{RESULTADOS E DISCUSSÕES}

O intuito da realização do grau de intumescimento é predizer o comportamento da membrana quando em solução PBS, analisando sua eficiência de absorção. Os resultados do 
grau de intumescimento estão apresentados na Tabela 1.

Tabela 1 - Grau de intumescimento

\begin{tabular}{|c|c|}
\hline $\begin{array}{c}\text { Tipo de } \\
\text { membrana }\end{array}$ & $\begin{array}{c}\text { GI (g solução PBS/ } \\
\text { g filme) }\end{array}$ \\
\hline $20 \%$ & $1,4211 \pm 0,1312$ \\
\hline $60 \%$ & $1,8071 \pm 0,4049$ \\
\hline
\end{tabular}

Nota-se pela Tabela 1 que a membrana que possui $60 \%$ em fração mássica de fibras apresentou um maior grau de intumescimento. Isso deve-se ao fato de que as fibras ajudam na absorção da solução. Portanto, ao se ter uma maior quantidade de fibras, uma maior quantidade de solução é absorvida.

A realização do teste mecânico é necessária visto que buscam-se membranas que sejam resistentes e maleáveis. A Figura 1 apresenta o gráfico típico obtido da tensão versus deformação para as membranas contendo $20 \%$ e $60 \%$ de fração mássica de fibras.

Figura 1 - Gráfico típico de tensão versus deformação para as membranas contendo $20 \%$ e $60 \%$ de fração mássica de fibras

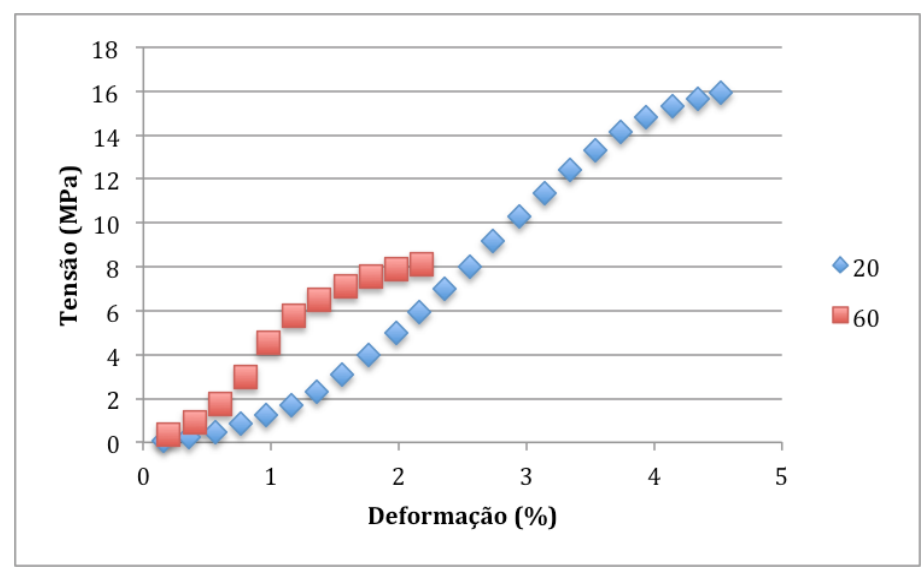

A Tabela 2 apresenta os dados médios da espessura, tensão e deformação de ruptura e o Módulo de Young das membranas.

Tabela 2 - Dados médios do teste mecânico para as membranas contendo $20 \%$ e $60 \%$ de fração mássica de fibras

\begin{tabular}{|c|c|c|c|c|}
\hline $\begin{array}{c}\text { Tipo de } \\
\text { membrana }\end{array}$ & Espessura (mm) & $\begin{array}{c}\text { Tensão de ruptura } \\
(\mathrm{MPa})\end{array}$ & $\begin{array}{c}\text { Elongação na } \\
\text { ruptura (\%) }\end{array}$ & $\begin{array}{c}\text { Módulo de Young } \\
(\mathrm{MPa})\end{array}$ \\
\hline $20 \%$ & $0,095 \pm 0,030$ & $18,743 \pm 5,860$ & $3,068 \pm 1,129$ & $10,499 \pm 5,167$ \\
\hline $60 \%$ & $0,165 \pm 0,062$ & $6,820 \pm 3,591$ & $2,416 \pm 0,732$ & $0,131 \pm 0,078$ \\
\hline
\end{tabular}


É possível perceber que a membrana de $20 \%$ apresentou maior resistência à tensão do que a de $60 \%$. Isso pode ser ao fato de que ao se preparar as membranas, encontrou-se certa dificuldade em homogeneizar as de $60 \%$, já que as fibras se emaranhavam pela alta quantidade presente na mistura de quitosana. Esse fato se evidencia no momento da medição da espessura, que por ser aleatório, por vezes encontrava-se um ponto muito mais elevado por concentração maior de fibra. Desta forma, ocorreu uma elevada variação das medidas de espessura das membranas com $60 \%$ de fibras, além de se ter uma baixa uniformidade da dispersão das fibras nas membranas, resultando em pontos mais susceptíveis à fratura durante o teste mecânico.

Além disso, nota-se que a membrana de $20 \%$ apresentou uma melhor maleabilidade do que a de $60 \%$, visto que os valores obtidos para a elongação na ruptura para a membrana de $20 \%$ foram maiores.

O intuito da análise da perda de massa durante a exposição em solução de PBS é predizer o comportamento da membrana, analisando sua estabilidade. Após a realização do teste, notou-se que tanto a membrana de $20 \%$ quanto a de $60 \%$ não apresentaram perda de massa, evidenciando a eficácia do processo de reticulação das membranas com a solução de hidróxido de sódio.

\section{CONCLUSÃO}

Ao se estudar as duas porcentagens em fração mássica de fibras nas membranas, pode-se perceber que ambas as membranas não apresentaram perda de massa. Sendo assim, a reticulação escolhida foi eficiente.

Já no caso do teste mecânico, notou-se que a membrana com $20 \%$ de fração mássica de fibras apresentou uma maior resistência mecânica. Entretanto, no caso de curativos, é necessário que, além de resistentes, sejam maleáveis. Portanto, não é apenas a resistência que deve ser estudada. A combinação da resistência mecânica e da maleabilidade é necessária. No caso da maleabilidade, notou-se que a membrana de $20 \%$ também apresentou melhor resultado.

Além disso, na análise do grau de intumescimento a membrana com $60 \%$ de fração mássica de fibras apresentou resultados melhores. Entretanto, mesmo a de $20 \%$ não apresentando resultado melhor do que a de $60 \%$ para o grau de intumescimento, analisando-se a combinação dos resultados de todos os testes realizados, a membrana com $20 \%$ de fração mássica de fibras apresentou uma melhor combinação de resultados.

\section{AGRADECIMENTO}

Agradecimento ao Conselho Nacional de Desenvolvimento Científico e Tecnológico (CNPq) pelo apoio financeiro e concessão de bolsa PIBIC. 


\section{NOMENCLATURA}

A: alongamento da ruptura em $\%$;

As: área da seção transversal da amostra do filme em $\mathrm{m}^{2}$;

di: afastamento inicial das garras $(0,05 \mathrm{~m})$;

dr: afastamento das garras no momento da ruptura em m;

Fm: força máxima de rompimento em $\mathrm{N}$;

GI: grau de intumescimento;

mf: massa final da amostra após realização do teste em g;

mi: massa inicial da amostra em g;

Mp: porcentagem de perda de massa em PBS;

TR: tensão de ruptura em $\mathrm{Pa}$.

\section{REFERÊNCIAS}

ALTMAN, G. H. et al. Silk-based biomaterials. Biomaterials, v. 24, n. 3, p. 401-416, Feb 2003. ISSN 0142-9612.

ASTM. Tensile properties of thin plastic sheeting. Annual Book of ASTM Standards, American Society for Testing and Materials, Philadelphia, D 882, 1995.

LI, M. Z. et al. Structure and properties of silk fibroin-poly (vinyl alcohol) gel. International Journal of Biological Macromolecules, v. 30, n. 2, p. 89-94, Apr 2002. ISSN 0141-8130.

PLAZA, G. R. et al. Effect of water on Bombyx mori regenerated silk fibers and its application in modifying their mechanical properties. Journal of Applied Polymer Science, v. 109, n. 3, p. 1793-1801, Aug 2008. ISSN 0021-8995.

VEPARI, C.; KAPLAN, D.L. Silk as biomaterial. Progress in Polymer Science, v. 32, n. 8-9, p. 991-1007, Aug-Sep 2007. ISSN 0079-6700. 